\title{
Research on Regional Industrial Structure Optimization Based on Independent Innovation
}

\author{
Wenjuan SONG \\ Wuhan Business University, Wuhan, 430056, China \\ 51295355@qq.com
}

\begin{abstract}
Keywords: Independent Innovation; Regional Industrial Structure Optimization; Industrial Structure Optimization
\end{abstract}

\begin{abstract}
Though many scholars have conducted a lot of studies on the importance of independent innovation in regional industrial structure optimization, the theoretical research on independent innovation and industrial structure optimization is relatively lacking. Thus, this paper attempts to rich and improve relative theories about independent innovation and industrial structure optimization based on the idea that independent innovation can promote structure optimization and the discussion of optimizing mechanism and methods. The author finds that regional economy will develop rapidly and steadily when regional industry center on independent innovation and focus on industrial structure optimization. And accordingly, an overall well-off area filled with independent innovation will come into being.
\end{abstract}

\section{Introduction}

The scientific and technological innovation based on independent innovation is not only the motivation of social economic development, but also the determining factor of regional economic development and industrial structure adjustment. [1]And the regional industrial structure optimization based on independent innovation is the key to transformation of economic growth pattern and raise of core competitiveness. [2]Thus, this paper elaborates on the positive effect of independent innovation on regional industrial structure optimization and its methods based on category definition of them and relative theories. [3]Besides, we also analyze the influencing mechanism of independent innovation on different industries so as to promote the development of three industries and conduct further study on the micro basis of the combination of independent innovation and regional industry. However, independent innovation relies a lot on external things like environment, policy. [4] [5] Thus, as an integrated idea, regional industrial structure optimization should not only pay great attention to independent innovation, but also attach great importance to the leading role of government. The regional government should create a sound environment, set supportive policy and standardize management system to support structure optimization. What's more, they should also encourage all social parties to join in the process of independent innovation and industrial structure optimization and finally promote the optimum allocation and efficient utilization of regional resources.

\section{Definition of Relative Terms}

\section{A. Industrial Structure}

Industrial structure means the proportion of different industries in the same economy and the proportion of resources held by different industries. Hence, to better optimize social resources and promote economic development, we should actively adjust and optimize industrial structure which actually covers structure rationalization and structure optimization. The structure rationalization means that all industries can promote each other while the structure optimization means that structure can keep continuous advancement based on structure rationalization.

B. Regional Industrial Structure

Regional industrial structure aims to rationalize the structure, proportion of regional departments, 
industries and their internal constitution. It is the organization form of regional economic system in certain economic area. Usually, because of different growth mechanisms and influencing mechanisms, the regional economic system keeps unbalanced development which drives the economic system to introduce investment, improve structure and keep continuous development. [6]It is obvious that the industrial structure is an important way for enterprises, the leading role in the economic system, to affect others. And the purpose of rationalizing industrial structure is to balance the polarization and other economic units and to make sure that the polarization and unbalanced development happen in the way that was expected.

C. Regional Industrial Structure Optimization

Regional industrial structure optimization is not only the consequent development of regional industrial structure, but also the inevitable result of regional economic growth and subjective function. The consequent development shows up as the rationalization of industrial structure and efficiency of industrial quality of all departments and industries so as to advance the level of industrial structure. [7] However, the rationalization and advancement of industrial structure are required to be based on certain regions and to formulate regional policy, decide industries and develop characteristic economy according to the bearing capacity, development level, development potential and function definition of regional resources

D. Independent Innovation

The establishment and analysis of the index system about regional innovation enjoy long history. The term "innovation" is firstly proposed by Joseph Schumpeter in The Theory of Economic Development. He states that innovation is equal to the creation of production function and it includes five aspects -- introducing new products, introducing new technology, opening up new market, controlling the source of raw materials and establishing new organization. But as for the basis connotation of regional innovative capacity, there is not an acknowledged answer yet at home and abroad. The capacity or competitiveness of regional science and technology isn't equal to the capacity of regional innovation, but they can reflect it effectively. Professor Potter and Professor Stern in Havard University insist that the level of national innovation capacity depends on the level of shared innovative facility and its interaction with regional innovation capacity under the background of innovation cluster.

\section{Hastening the Appearance of Regional Emerging Industry}

Independent innovation is the source and motivation of the establishment of emerging industry. Kuznets holds the idea that industry evolution, as the result of technological innovation, decides the progress of development. To be specific, for the leading industry, in the late maturity stage, the income elasticity of demand decreases, the capital supply growth slows down, the market saturates and the production growth slows down or even shows up negative growth. At the same time, the former second leading industry will develop rapidly; expand its scale similar to that of the former leading industry. And these all realize the industry evolution.

A. Independent Innovation will Hasten the Appearance of Emerging Industry

Efficient independent innovation, as practical activities of economy, science and technology, can promote industrial optimization, upgrading and economic development. In the regional economic system, independent innovation should take active part in high-tech research and take full advantage of space superiority. Inspired by innovation, location, resource and talents are fully utilized and accordingly promote the rationalization of industrial structure, the regionalization of high-tech products and the appearance of emerging industry.

B. Independent Innovation will Hasten the Rationalization and Advancement of Regional Industrial Structure

Independent innovation will rationalize the proportion of all industries in that scientific and technological innovation can propel the self-improvement of industrial chain, the evolution of modern industrial sectors and elimination of those backward low-productivity sectors. Besides, scientific and technological innovation will advance all industries, largely improve the technological level and efficiency and promote the advanced development of regional industrial 
structure. After these actions, regional industrial structure will develop rapidly and finally propel economic development and improve socio-economic benefits.

C. Independent Innovation will Optimize Regional Division and Improve Professional Level

The change and development of regional industrial structure are closely connected with regional division. In fact, in the national system of industrial structure, regional industrial structure can experience an integral evolution only when it participates in international division. And different industrial structures evolve in different ways in the integral evolution, which actually reflects the characters of each region in the system of regional division. In the past, many regions stuck to the idea of small but all-inclusive or large but all-inclusive which resulted in the weak connection among enterprises and regions. However, the appearance of the idea of independent innovation largely increases competitiveness of those regions used to be in passive position, narrows the gap among different industrial sectors and closely link the technologies of leading industries and assistance industries. As a result, regional industrial sectors can better participate in industry division and regional industrial structure can enjoy long-term healthy development and improvement.

\section{Mechanism of Regional Industrial Structure Optimization}

Independent innovation indirectly promotes industrial structure optimization by leading to the adjustment of employment structure of labor force, consumption structure, regional structure, trade pattern and so on.

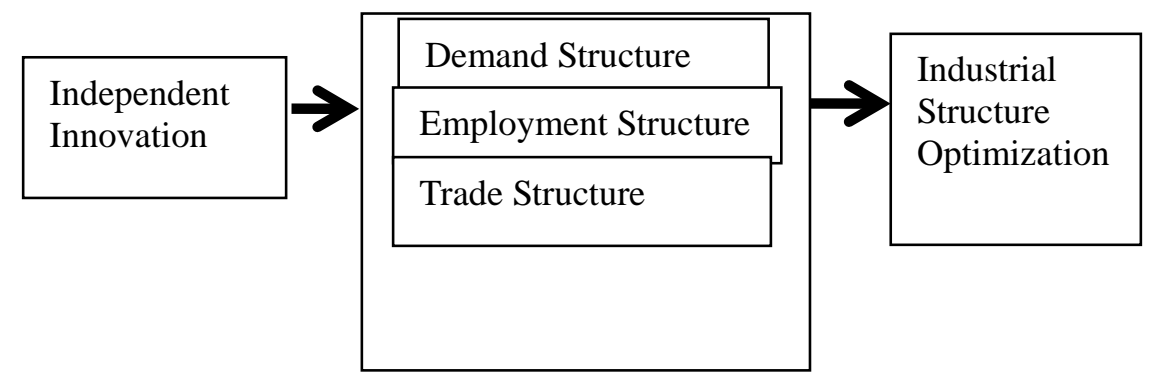

Figure 1. Mechanism of regional industrial structure optimization based on independent Innovation

A. Demand Structure

Independent innovation largely influences demand structure. Usually, the technology of those industrial sectors with urgent need and significant effect on economy will advance more quickly. To some extend, demand decides the direction and speed of independent innovation. In other words, technological breakthrough will largely stimulate new demand; promote structure optimization while stereotyped technology will weaken the positive effect of demand structure on industrial structure. On one hand, innovation will help reduce the cost of products, expand the market and stimulate the demand. On the other hand, demand structure is the basis of independent innovation. Thus, only the innovation complying with demand is successful and innovation will adjust the demand structure of investment and optimize the allocation of resources.

B. Employment Structure

Employment structure, as a typical form of industrial structure, is a bridge between technological progress and industrial structure. To be specific, firstly, innovation is the basis of the employment structure adjustment of labor force while the productivity improvement directly decides the adjustment of industrial structure which consists of structure of labor force and output value. Secondly, innovation propels the specialization and division of labor. To be specific, the technological progress will contribute to the refinement of social division, the rationalization of the ratio of physical work and mental work and accordingly the adjustment of employment structure and industrial structure. Thirdly, innovation does good to improve the quality of human resources which positively correlates with technological progress. Finally, innovation is able to improve thee substituted structure of factors. According to the Neo-classical School, technological progress can decrease restrain factors like adjusting the price of labor force and other factors, changing the 
influencing degree of capital so as to improve the substituted structure of technology.

C. Trade Structure

The Technology Gap Theory proposed by Posner and the Product Life Cycle Theory proposed by Vernon stress the importance of technological progress from different perspectives and both treat it as major factors and determining factor of international and regional comparative advantage. Hence, the difference of international trade is essentially equal to the difference of technology and structure. On one hand, innovation affects international trade pattern by affecting international competitiveness. It is true that market competitiveness usually depends on cost, quality, added value and brand which are all closely connected with innovation and are all typical forms of innovation. On the other hand, innovation is closely linked with technological barrier which is nowadays the most hidden and the most difficult trade barrier. Accordingly, technological competitiveness becomes the core of international trade competition. Thus, the high requirement of technical standards can promote technological innovation, improve productivity, adjust industrial structure and propel the optimization and efficient utilization of social resources.

\section{Conclusion}

Above all, independent innovation and industrial structure optimization should be analyzed ad realized in certain region. Under the help of the leading function of government, the subjective function of enterprises, the guidance of college research institutes and the fundamental role of the market in the allocation of resources, independent innovation can greatly promote the optimization of regional industrial structure, inspire further innovations and build innovative areas. This paper proposes that independent innovation is the key and motivation of regional industrial structure optimization based on the analysis of structure optimization and methods for its realization. In short, innovation can on one hand promote regional industrial structure optimization, take full advantage of each region and propel coordinated development of regional economy. And on the other hand, it can transform the economic growth mode and completely change the status quo of high investment, low productivity, high consumption and low profit.

\section{Acknowledgement}

In this paper, the research was sponsored by Innovative Investment and Regional Industrial Structure Optimization, Supported by the Education Department of Hubei Province. (Project No. B2015386,) and R\&D Subsidies of Government and Technological Innovation of SMEs, Supported by Wuhan Business School. (Project No. 2014A004).

\section{References}

[1]Corporate Benefits from Universal Banking: Germany and the United States.1870-1914.”. Calomiris, Charles. NBER Working Paper No.4408 . 1993

[2]A Financial Analysis of Acquisition and Merger Premiums. Nielsen,J. F,R. W Melicher. The Journal of Finance. 1973

[3]Singapore: Wealth, power and the culture of control. CA Trocki. . 2006

[4]Singapore in Southeast Asia: An Economic and Political Appraisal. lain Buchanan. . 1972

[5]Fluid nation: The perpetual "renovation of nation and national identities. Chong,T. Management of success: Singapore revisited . 2010

[6]Entry restrictions, Industry Evolution, and Dynamic Efficiency: Evidence from Commercial Banking. Jith Jayaratne, Philip Straham. J.L.and Econ . 1998

[7]Ownership and Control: Rethinking Corporate Governance for the Twenty-first Century. Blair, Margaret M. 1995 